\title{
Transduction of $\mathrm{Gal}^{+}$by Coliphage T1
}

\section{Role of Hybrids of Bacterial and Prophage $\lambda$ Deoxyribonucleic Acid}

\author{
HENRY DREXLER \\ Department of Microbiology, The Bowman Gray School of Medicine of Wake Forest University, \\ Winston-Salem, North Carolina 27103
}

Received for publication 13 September 1971

\begin{abstract}
Hybrids of $\lambda$ and adjacent bacterial deoxyribonucleic acid carried in T1 particles were able to transduce $\mathrm{Gal}^{+}$with a greatly increased efficiency to strains which were not immune to $\lambda$ compared to immune strains. The enhanced transduction was dependent on a functional $\mathrm{rec}^{+}$gene in the recipient. Mutations of the donor's $\lambda$ prophage which abolished the function of either the $\mathrm{cI}, \mathrm{O}$, or $\mathrm{P}$ genes in the recipients led to a further enhancement of transduction. The rate of transduction of a nonlysogenic recipient such as W3350 by the hybrid particles may be as much as 140 times greater than transduction of the lysogenic recipient $W 3350(\lambda)$. In addition to the effect of $\lambda$ immunity in blocking enhanced transduction, mutations of the $\mathbf{N}$ gene of the donor's $\lambda$ prophage abolished enhanced transduction. Mutations in the red, int, xis, and Q genes of the donor's prophage had no significant effect on transduction. The hybrids which mediated the enhanced transduction are called $(\lambda-g a l) \mathrm{T} 1$.
\end{abstract}

In a previous report, it was shown that the virulent coliphage T1 is able to mediate generalized transduction between $\mathrm{K}$ strains of Escherichia coli. The production of progeny $\mathrm{T} 1$ particles, a process which might lead to subsequent lysis of transductants, was prevented by using conditional lethal mutants of $\mathrm{T} 1$ that are not productive in the recipients (7).

By using $\mathrm{T} 1$ as a transducing phage, it was observed that the transducing frequency for the ability to ferment galactose is influenced by the presence of $\lambda$ in the donor and recipient. Data will be presented which demonstrate that T1 grown on cells lysogenic for $\lambda$ is able to transduce cells which are not lysogenic for $\lambda$ at an increased rate compared to recipients which are lysogenic for $\lambda$.

In this report, the presence of certain mutations in the donor's $\lambda$ prophage will be tested to determine their effect on the rate of transduction of $\mathrm{Gal}^{+}$by $\mathrm{T} 1$. It will be shown that transductional enhancement is mediated by a hybrid of bacterial and phage $\lambda$ deoxyribonucleic acid (DNA); the hybrid particles are abbreviated as $(\lambda-g a l) \mathrm{T} 1$.

\section{MATERIALS AND METHODS}

Materials. Complete eosin methylene blue agar with galactose (EMB-gal) has been described elsewhere (14).

The strains of $E$. coli $\mathrm{K}$ and of bacteriophage utilized in this report are given in Tables 1 and 2, respectively.
Lysates of T1am grown on $\mathrm{Su}^{+}$donor cells lysogenic for phage $\lambda$ are contaminated with $\lambda$ particles. To reduce the number of plaque-forming units of $\lambda$ to less than $10^{-6}$ per plaque-forming unit of $T 1$, the lysates were treated in one of two ways. (i) The lysates were exposed to a dense concentration of $E$. coli $\mathrm{K} / 1$, a strain which was isolated in this laboratory and which will adsorb $\lambda$ but not T1. (ii) The lysates were exposed to anti- $\lambda$ serum kindly provided by $D$. Kennell.

The calculation of the efficiency of transduction (EOT) has been described in a previous publication (7).

A brief description of the conditions under which the transduction experiments were performed is given in the footnote of Table 3. A more detailed description may be obtained elsewhere (7).

\section{RESULTS}

Effect of $\lambda$ lysogeny and $\lambda$ immunity on transduction. Since T1am is able to transduce the $\mathrm{Gal}^{+}$phenotype from $\mathrm{Gal}^{+}$donors to $\mathrm{Gal}^{-}$ recipients (7), experiments were done to determine what effect the presence of a $\lambda$ prophage in either the donor or recipient cells has on the rate of transduction of $\mathrm{Gal}^{+}$. Results (Table 3) show that the EOT of $\mathrm{Gal}^{+}$is reproducible within a two- to threefold range. Such reproducibility is typical for transduction mediated by $\mathrm{T} 1$ for a variety of markers (Drexler, unpublished observations) and adds a degree of quantitation to the transduction data presented in this report.

The presence of a $\lambda$ prophage in either the donor or the recipient can cause a significant 
TABLE 1. Types of Escherichia coli strain $K^{a}$

\begin{tabular}{|c|c|c|c|}
\hline Designation & Pertinent phenotype & Source & Reference \\
\hline $\begin{array}{l}\text { KB-3 } \\
\text { KB-3 }(\lambda)\end{array}$ & $\begin{array}{l}\mathrm{Su}^{+} \mathrm{Gal}^{+} \\
\mathrm{KB}-3 \text { lysogenized with wild- } \\
\quad \text { type } \lambda\end{array}$ & W. Michalke & 15 \\
\hline W3350 & $\mathrm{Su}^{-} \mathrm{Gal}^{-}$ & E. Six & 3 \\
\hline $\mathrm{W} 3350(\lambda)$ & $\begin{array}{l}\text { W3350 lysogenized with wild- } \\
\text { type } \lambda\end{array}$ & & \\
\hline $\mathrm{W} 3350\left(\lambda \mathrm{h}_{80}\right)$ & W3350 lyosogenized with $\lambda h_{80}$ & & \\
\hline MR42 & $\mathrm{Su}^{-} \mathrm{Gal}^{-} \mathrm{Rec}^{+}$ & E. Signer & 19 \\
\hline MR43 & $\mathrm{Su}^{-} \mathrm{Gal}^{-} \mathrm{Rec}^{-}$ & E. Signer & 21 \\
\hline $\operatorname{MR} 43(\lambda)$ & $\begin{array}{l}\text { MR43 lysogenized with wild- } \\
\text { type } \lambda\end{array}$ & & \\
\hline $\begin{array}{l}\text { K704 } \\
\text { K704 }(\lambda d e l)\end{array}$ & $\begin{array}{l}\mathrm{Su}^{+} \mathrm{Gal}^{-} \\
\mathrm{K} 704 \text { lysogenic for } \lambda \text { contains a } \\
\quad \text { deletion from } \lambda \mathrm{B} \text { through } \operatorname{chl} A\end{array}$ & R. J. Huskey & 26 \\
\hline
\end{tabular}

a Bacterial phenotypes are designated by an abbreviation which begins with a capital letter and is described as + (i.e., functional) or - (i.e., nonfunctional). Genotypes are symbolized by the standard terminology of Taylor (25). Abbreviations: $\mathrm{Su}^{+}$, suppresses sus or amber mutations; $\mathrm{Su}^{-}$, does not suppress sus or amber mutations; $\mathrm{Gal}^{+}$, able to ferment galactose; $\mathrm{Gal}^{-}$, not able to ferment galactose; $\mathrm{Rec}^{+}$, possess a rec ${ }^{+}$gene; $\operatorname{Rec}^{-}$, possess the $\operatorname{rec} A$ mutation $(5,10)$. Variations of phage $\lambda$ that were used to lysogenize KB-3 are given in Table 2.

TABLE 2. Strains of bacteriophage $e^{a}$

\begin{tabular}{|c|c|c|c|}
\hline $\begin{array}{l}\text { Designa- } \\
\text { tion }\end{array}$ & Genotype & Source & $\begin{array}{l}\text { Refer- } \\
\text { ence }\end{array}$ \\
\hline$\lambda$ & Wild-type $\lambda$ & E. Six & 13 \\
\hline 入red & $\lambda_{\text {red }} 3$ & R. J. Huskey & 20 \\
\hline$\lambda$ int & $\lambda_{\text {int }}$ sus $29_{1}$ & M. Howe & 20 \\
\hline$\lambda \mathrm{cI}_{\mathrm{t}} x i s$ & $\lambda \mathrm{CI}_{\mathrm{t} 857} x i s_{\text {sus } 6}$ & M. Howe & 9 \\
\hline$\lambda \mathrm{O}$ & $\lambda \mathrm{O}_{\text {sus } 8}$ & R. J. Huskey & 3 \\
\hline$\lambda c I_{t} \mathbf{P}$ & $\lambda_{c I_{\mathrm{t1}} \mathbf{P}_{\text {sus } 422}}$ & R. J. Huskey & \\
\hline$\lambda N$ & $\lambda c I_{t 857} \mathbf{N}_{s u s 7} \mathbf{N}_{s u s 53}$ & R. J. Huskey & 19 \\
\hline$\lambda Q$ & $\lambda Q_{s u s 73}$ & M. Howe & 3 \\
\hline$\lambda h_{8 n}$ & Hybrid of $\lambda$ and 180 & E. Signer & 18 \\
\hline T1am & Tlam ${ }_{5} a m_{11}$ & & 7 \\
\hline
\end{tabular}

${ }^{a}$ Symbols which describe $\lambda$ mutations are traditional. All but one of the mutations used in this report has a designation as sus (i.e., suppressed by $\mathrm{Su}^{+}$cells) or $\mathrm{t}$ (i.e., it produces a product inactivated at $42 \mathrm{C}$ but generally stable at $35 \mathrm{C}$ ); the red mutation is not a conditional lethal mutation. Number which is used with the phage mutations distinguishes the particular mutation from all other isolates which are mutated in the same gene. The meaning of the various $\lambda$ mutations is given in the text. The am (or amber) mutations of T1 are suppressed by $\mathrm{Su}^{+}$cells.

alteration in the EOT. When $\mathrm{KB}-3(\lambda)$ is the donor and W3350 the recipient, the EOT is increased about 35 - to 40 -fold over that observed when KB-3 is the donor or when W3350( $\lambda)$ is the recipient (Table 3). Since enhancement of $\mathrm{Gal}^{+}$ transduction requires the presence of prophage $\lambda$ in the donor together with the absence of $\lambda$ in the recipient, a simple conclusion would be that the cotransduction of $\mathrm{Gal}^{+}$together with an immunity-sensitive function of prophage $\lambda$ is responsible for the enhancement.
To determine whether the reduced level of transduction in $\lambda$ lysogenic recipients was due to the presence of $\lambda$ immunity or a steric effect caused by the proximity of prophage $\lambda$ to the galactose operon (Fig. 1), recipients lysogenic for $\lambda h_{80}$ were employed. The phage $\lambda h_{80}$ is a hybrid of phage $\lambda$ and phage $\phi 80$. Phage $\lambda h_{80}$ has the chromosomal attachment site of $\phi 80$ (a site which is not in the vicinity of the galactose operon) and the immunity gene of $\lambda(18)$. Data show that recipients lysogenic for $\lambda h_{80}$ reduce transduction of $\mathrm{Gal}^{+}$from $\lambda$ lysogenic donors to about the same extent as cells lysogenic for $\lambda$ (Table 3). Further evidence supporting the idea that the immunity repressor of $\lambda$ ( $=$ product of $\mathrm{cI}^{+}$gene) blocks enhanced transduction will be presented in a subsequent experiment. It is concluded, therefore, that reduction of enhanced transduction mediated by $\mathrm{T} 1 \mathrm{am} \cdot \mathrm{KB}-3(\lambda)$ (i.e., T1 am grown on strain KB-3 lysogenic for phage $\lambda$ ) must be due to the immunity repressor of $\lambda$ rather than steric hinderance.

Mechanism of incorporation of Gal leading to enhanced transduction. The purpose of these experiments was to determine whether the incorporation of $\mathrm{Gal}^{+}$is the result of a nonspecific mechanism of recombination, which is under the control of $\lambda$, or the result of a recombination mechanism of the bacterium, namely the $\mathrm{Rec}^{+}$ system $(5,10)$.

Strains MR42 and MR43 are nearly isogenic but are $\operatorname{Rec}^{+}$and $\operatorname{Rec}^{-}$, respectively $(19,21)$. Results show that whenever T1am $\cdot \mathrm{KB}-3$ is used to transduce either MR42 or MR43 it is not pos- 
TABLE 3. Influence of a $\lambda$ prophage on the transduction of $\mathrm{Gal}^{+}$between strains of Escherichia coli ${ }^{a}$

\begin{tabular}{|c|c|c|c|c|c|}
\hline \multirow{2}{*}{$\mathrm{Su}^{+} \mathrm{Gal}^{+}$donor } & \multirow{2}{*}{$\mathrm{Su}^{-\mathrm{Gal}^{-} \text {recipient }}$} & \multirow{2}{*}{$\begin{array}{c}\text { No. of } \\
\text { Expt }\end{array}$} & \multicolumn{3}{|c|}{ Efficiency of transduction } \\
\hline & & & $\begin{array}{l}\text { Lowest value } \\
\text { observed }\end{array}$ & $\begin{array}{l}\text { Highest value } \\
\text { observed }\end{array}$ & Avg \\
\hline KB-3 & W3350 & 5 & $2.6 \times 10^{-7}$ & $5.4 \times 10^{-7}$ & $3.9 \times 10^{-7}$ \\
\hline KB-3 & W3350 $(\lambda)$ & 3 & $3.5 \times 10^{-7}$ & $4.6 \times 10^{-7}$ & $4.0 \times 10^{-7}$ \\
\hline KB-3 $(\lambda)$ & W3350 & 8 & $8.7 \times 10^{-6}$ & $1.8 \times 10^{-5}$ & $1.3 \times 10^{-5}$ \\
\hline KB-3 $(\lambda)$ & $\mathrm{W} 3350(\lambda)$ & 6 & $2.5 \times 10^{-7}$ & $7.8 \times 10^{-7}$ & $4.6 \times 10^{-7}$ \\
\hline $\mathrm{KB}-3(\lambda)$ & $\mathrm{W} 3350\left(\lambda \mathrm{h}_{80}\right)$ & 3 & $5.3 \times 10^{-7}$ & $8.6 \times 10^{-7}$ & $7.4 \times 10^{-7}$ \\
\hline
\end{tabular}

a $\mathrm{Tlam}$ phage which had been grown on $\mathrm{Su}^{+} \mathrm{Gal}^{+}$donors was used to infect $\mathrm{Su}^{-} \mathrm{Gal}^{-}$recipients. After a short incubation, the mixture of cells and phage was spread, at appropriate dilutions, onto EMB-gal (eosin methylene blue agar with galactose) plates which were then incubated at $37 \mathrm{C}$.

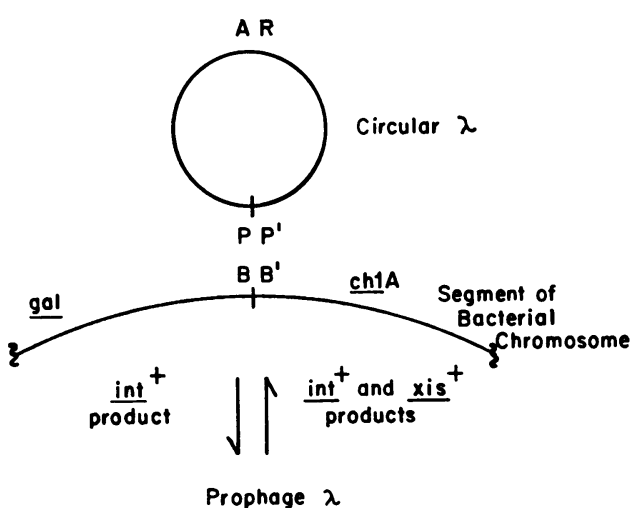

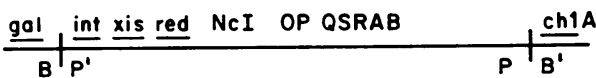

FIG. 1. Figure is adapted from figures produced in many publications; for example, see references 8 and 9. The genetic markers are oriented properly but the distances between them are not drawn to scale.

sible to transduce a $\mathrm{Rec}^{-}$recipient (Table 4). These data demonstrate the normal dependence of transduction on a functioning Rec system.

When T1am $\cdot \mathrm{KB}-3(\lambda)$ is used to transduce MR42 and MR43, it was observed that over $99 \%$ of the transduction depends on a functioning $\mathrm{Rec}^{+}$system (Table 4). Therefore, actual incorporation of donor DNA leading to the enhanced transduction of $\mathrm{Gal}^{+}$from $\lambda$ lysogenic donors to nonlysogenic recipients is mediated by the recombination mechanism of the bacterium.

However, the limited transduction observed when T1am $\cdot \mathrm{KB}-3(\lambda)$ is used to transduce MR43 does seem to be under the control of a $\lambda$ gene product since lysogenization of MR43 with $\lambda$ greatly reduces the remaining ability of $(\lambda-g a l) \mathrm{T} 1$ to transduce (Table 4).

The red gene (or system) of $\lambda$ controls general recombination $(8,20)$; experiments which specifically tested the role of this gene were performed (Table 5). By using donors lysogenic for $\lambda r e d$, it was found that the presence of a red mutation in the donor's prophage has no effect on the EOT for $\mathrm{Gal}^{+}$.

In conclusion, enhanced transduction requires the functioning of a general recombination mechanism of the recipient (the $\mathrm{Rec}^{+}$system) but does not require a functioning $\mathrm{red}^{+}$system.

Role of lysogenization in enhanced transduction. Since the presence of a $\lambda$ prophage in the donor cells is required for enhanced transduction of $\mathrm{Gal}^{+}$and the enhancement is sensitive to the presence of $\lambda$ immunity in the recipient, it is assumed that the enhancement is due to a function(s) of $\lambda$ genes which are cotransduced with the $\mathrm{Gal}^{+}$marker. The results presented here were gathered to determine whether the $\mathrm{Gal}^{+}$characteristic becomes associated with the recipients through lysogenization by the chromosome of $(\lambda-$ gal $)$ T1 . It has been shown by others $(1,2$, $16,17)$ that transduction of $\mathrm{Gal}^{+}$that is mediated by the hybrid particle $\lambda d g$ usually results in a lysogenization of transductants by the chromosome of $\lambda \mathrm{dg}$. Further, cells which become transduced for $\mathrm{Gal}^{+}$by virtue of being lysogenic for $\lambda \mathrm{dg}$ are immune to $\lambda$ and unstable for the $\mathrm{Gal}^{+}$ phenotype. Cells which maintain $\lambda \mathrm{dg}$ as a plasmid also are unstable for $\mathrm{Gal}^{+}$and immune to $\lambda$ (19).

Over 400 transductants were isolated from experiments in which T1 am $\cdot \mathrm{KB}-3(\lambda)$ was used to transduce W3350 (Table 3). The $\mathrm{Gal}^{+}$isolates were purified by restreaking and tested for both immunity to $\lambda$ and stability of $\mathrm{Gal}^{+}$phenotype. None of the isolates was immune to $\lambda$ and all were stable for $\mathrm{Gal}^{+}$(results not shown). Thus, 
TABLE 4. Efficiency of transduction of $\mathrm{Gal}^{+}$to $\mathrm{Rec}^{+}$and Rec ${ }^{-}$strains of Escherichia coli

\begin{tabular}{|c|c|c|c|}
\hline \multirow{2}{*}{$\mathrm{Su}^{+} \mathrm{Gal}^{+}$donor } & \multicolumn{3}{|c|}{$\mathrm{Su}^{-} \mathrm{Gal}^{-}$recipients } \\
\hline & MR42-Rec ${ }^{+}$ & MR43-Rec ${ }^{-}$ & $\operatorname{MR} 43(\lambda) \cdot \operatorname{Rec}^{-}$ \\
\hline $\begin{array}{l}\text { KB-3 } \\
\text { KB-3 }(\lambda)\end{array}$ & $\begin{array}{l}3.7 \times 10^{-7}(2)^{a} \\
1.6 \times 10^{-5}(2)\end{array}$ & $\begin{array}{l}<4 \times 10^{-10}(2) \\
9.0 \times 10^{-8}\end{array}$ & $<5 \times 10^{-10}(2)$ \\
\hline
\end{tabular}

${ }^{a}$ Numbers in parentheses indicate the number of experiments on which the given average is based. See footnote of Table 3 for experimental details.

TABLE 5. Efficiency of transduction of W3350 and W3350(ג) with Tlam grown on various donors

\begin{tabular}{|c|c|c|c|}
\hline \multirow{2}{*}{ Donor } & \multirow{2}{*}{$\begin{array}{l}\text { Incubation } \\
\text { temp (C) }\end{array}$} & \multicolumn{2}{|c|}{ Recipient } \\
\hline & & W3350 & 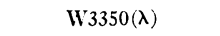 \\
\hline $\mathrm{KB}-3(\lambda)$ & 42 & $1.4 \times 10^{-5}(2)^{a}$ & $3.6 \times 10^{-7}(1)$ \\
\hline KB-3(Ared) & 35 & $1.4 \times 10^{-5}$ & $3.9 \times 10^{-7}(1)$ \\
\hline KB-3( int $)$ & 35 & $2.0 \times 10^{-5}(2)$ & $9.4 \times 10^{-7}(5)$ \\
\hline KB-3 $\left(\lambda c I_{t} x i s\right)$ & 35 & $1.8 \times 10^{-5}(2)$ & $9.0 \times 10^{-7}(2)$ \\
\hline $\mathrm{KB}-3\left(\lambda c I_{\mathrm{t}}\right.$ xis $)$ & 42 & $4.6 \times 10^{-5}$ & $8.7 \times 10^{-7}$ \\
\hline $\mathrm{KB}-3(\lambda \mathrm{O})$ & 35 & $5.1 \times 10^{-5}$ & $5.2 \times 10^{-7}(2)$ \\
\hline $\mathrm{KB}-3\left(\lambda c I_{t} \mathrm{P}\right)$ & 35 & $4.1 \times 10^{-5}$ & $6.0 \times 10^{-7}(2)$ \\
\hline $\mathrm{KB}-3\left(\lambda c I_{t} \mathrm{P}\right)$ & 42 & $7.0 \times 10^{-5}$ & $4.9 \times 10^{-7}(2)$ \\
\hline $\mathrm{KB}-3(\lambda \mathrm{N})$ & 35 & $8.1 \times 10^{-7}$ & $2.7 \times 10^{-7}(4)$ \\
\hline $\mathrm{KB}-3(\lambda \mathrm{Q})$ & 35 & $7.5 \times 10^{-6}$ & $3.3 \times 10^{-7}$ \\
\hline K704(入del) & 35 & $7.5 \times 10^{-6}$ & $1.6 \times 10^{-7}(2)$ \\
\hline
\end{tabular}

a Numbers in parentheses indicate the number of experiments on which the given average is based. See footnote of Table 3 for experimental details.

transductants formed by $\lambda$-gal hybrids carried by $\mathrm{T} 1$ appear to be transduced by a different mechanism than cells transduced by $\lambda d g$.

Role of site-specific recombination in enhanced transduction. Figure 1 shows that a $\lambda$-gal hybrid would contain the left prophage attachment site, namely the B.P' site. To determine the possible role of specific recombination between B.P' and B. $\mathbf{B}^{\prime}$ (the normal bacterial attachment site for $\lambda)$, experiments were performed to test the effect of mutations in the $\lambda$ genes which control sitespecific recombination. It can be seen in Fig. 1 that the product of the $i n t^{+}$gene is required for integration of $\lambda$ into the chromosome of the bacterium (27), whereas the products of both the int $^{+}$and $x i s^{+}$genes are required for prophage excision (9).

Table 5 presents data which show that a donor whose prophage contains an int mutation can transduce as efficiently as a donor lysogenic for $\lambda$. Data in Tables 3 and 5 also show that KB-3( $\lambda$ xis) serves as a donor as efficiently as KB-3 $(\lambda)$. (Note the $\lambda x i s$ results referred to here are those obtained at $35 \mathrm{C}$; the results obtained at $42 \mathrm{C}$ will be explained in the next section.)

It is concluded that site-specific recombination, which is mediated by the products of the int $^{+}$and $x^{+}$s $^{+}$genes of $\lambda$, plays no role in enhanced transduction by $(\lambda-g a l) \mathrm{T} 1$.

$\lambda$ Mutations which increase the transduction of $\mathrm{Gal}^{+}$. Autonomous replication of $\lambda$ DNA requires the products of both the $\mathrm{O}^{+}$and $\mathrm{P}^{+}$genes (11). To determine whether $\lambda$ DNA replication caused an increase in recombination $(23,24)$ which led to an increased transduction of $\mathrm{Gal}^{+}$, T1am grown on donors lysogenic for a $\lambda$ prophage containing either an $\mathrm{O}$ or a $\mathrm{P}$ mutation were tested. Results show that under normal conditions (35 C) T1 am grown on donors lysogenic for $\lambda$ with either an $\mathrm{O}$ or $\mathbf{P}$ mutation bring about a consistent two- to threefold increase in the EOT. The data confirm the assumption that enhanced transduction is mediated by a hybrid of $\lambda$ and bacterial DNA by showing that the presence of certain conditional lethal mutations of $\lambda$, which are suppressed in the donor but not the recipient, can cause alterations in the EOT. In other words, the activity of donor $\lambda$ genes in the recipient influence the rate of transduction. The data also show that $\lambda$ DNA replication in the recipient is not responsible for enhanced transduction. Furthermore, $\lambda$ DNA replication (or the products leading to replication) may interfere with transduction. 
An examination of the genotypes listed in Table 2 shows that certain of the $\lambda$ phages contain a mutation of the cI (immunity) gene. A cIt mutation results in the production of a temperature-sensitive immunity repressor. To test the effect of the expression of the donor's cI gene on the EOT, experiments were performed at $42 \mathrm{C}$. On the one hand, data show that raising the temperature from 35 to $42 \mathrm{C}$ has no effect on transduction which utilizes $\mathrm{KB}-3(\lambda)$ as a donor (Table 5). On the other hand, T1am $\cdot \mathrm{KB}-3\left(\lambda_{c \mathrm{I}} \mathrm{I}_{\mathrm{t}}\right.$ $x i s)$ is able to transduce W3350 more efficiently at 42 than at $35 \mathrm{C}$; the same is true of T1 am $\cdot \mathrm{KB}$ $3\left(\lambda c I_{t} P\right.$ ) (Table 5). Comparing the results (Table 5) obtained at 35 and $42 \mathrm{C}$ for the donor $\mathrm{KB}$ $3\left(\lambda \mathrm{cI}_{t} \mathrm{P}\right)$ does not determine whether the elevation of transduction caused by the presence of a $\mathbf{P}$ mutation in the donor's prophage and the increase caused by inactivating the immunity repressor are distinct and additive effects. Comparing the EOT of T1am $\cdot \mathrm{KB}-3\left(\lambda_{\mathrm{cI}} \mathrm{P}\right)$ at $42 \mathrm{C}$ on the $\mathrm{W} 3350$ to $\mathrm{W} 3350(\lambda)$ recipients reveals a 140-fold enhancement in transduction; this is the largest enhancement observed in this report. The effect observed by inactivating cI repressor produced by $(\lambda-g a l) \mathrm{T} 1$ confirms the assumption that enhanced transduction is blocked by immunity repressor and at the same time supports the idea that one or more gene products of $\lambda$ are required for enhanced transduction to occur.

$\lambda$ Mutation which decreases the transduction of $\mathrm{Gal}^{+}$. The $\mathbf{N}^{+}$gene of $\lambda$ makes a product which exerts a positive control over transcription of the $\lambda$ chromosome (22). The results obtained when T1 am phage grown on donors lysogenic for $\lambda \mathrm{N}$ were used to donate $\mathrm{Gal}^{+}$to W3350 are given in Table 5. The data show that mutations in $\mathrm{N}$ cause a significant reduction in the ability of T1am grown on a $\lambda$ lysogenic donor to donate $\mathrm{Gal}^{+}$to $\mathrm{Gal}^{-}$recipients. These data confirm the hypothesis that enhanced transduction is mediated by $(\lambda-g a l) \mathrm{T} 1$ hybrids and that certain $\lambda$ genes must function in the recipient for enhancement to take place.

$\lambda$ Mutations which have no effect on transduction of $\mathrm{Gal}^{+}$. It has already been demonstrated that the $\lambda$ mutations red, int, and xis have no effect on the EOT of $\mathrm{Gal}^{+}$. Here the effect of the late $\lambda$ functions (lysis, coat, and tail proteins) are tested. Efficient production of late functions is under the direct pesitive control of a product made by gene $\mathrm{Q}^{+}(6)$. When $\mathrm{KB}-3(\lambda \mathrm{Q})$ is used as a donor, there is a consistent depression of the EOT (Table 5); nevertheless, there remains a 20 -fold enhancement. It is, therefore, concluded that the gene product of $\mathrm{Q}^{+}$(and by implication the products of all genes under the control of $\mathbf{Q}^{+}$) is not required for enhanced transduction, although the product of a late gene may have a supplementary influence on the enhancement.

It is possible that not all genes to the right of $Q$ on the $\lambda$ prophage are under the control of $\mathrm{Q}^{+}$. To test the possible effect of a gene to the right of the region controlled by Q, strain K704( $\lambda$ del) was used as the donor. Strain K704( $\lambda$ del) is lysogenic for $\lambda$ and contains a deletion of all prophage DNA to the right of (and including) gene B. Results show that T1am grown on $\mathrm{K} 704(\lambda \mathrm{del})$ transduces at the same efficiency as T1 am $\cdot \mathrm{KB}-3-(\lambda \mathrm{Q})$ (Table 5). Therefore, none of the functions produced by genes to the right of gene B are responsible for enhanced transduction.

\section{DISCUSSION}

An enhancement of the transduction of $E$. coli for the $\mathrm{Gal}^{+}$phenotype has been observed. Enhanced transduction occurs when T1am phage, which has been grown on a $\mathrm{Gal}^{+}$donor lysogenic for $\lambda$, is used to transduce $\mathrm{Gal}^{-}$recipients which are not lysogenic for $\lambda$ (Table 3 ). The immunity caused by a $\lambda$ prophage located either near or at a distance from the galactose operon is able to block enhanced transduction. Further, production of immunity repressor in recipients by the cI gene of transferred donor DNA can also reduce the EOT (Table 5). Enhanced transduction is almost completely dependent on the $\mathrm{Rec}^{+}$system of the recipient (Table 4). Mutations in the $\mathbf{O}$ and $\mathbf{P}$ genes in the donor prophage result in a rise in the level of transduction, whereas a mutation of the $\mathbf{N}$ gene almost completely abolishes transduction (Table 5). None of the following donor prophages significantly affected the ability of a lysogenic cell to serve as a donor: $\lambda$ red, $\lambda$ int, $\lambda x i s, \lambda Q$, and $\lambda$ deleted from gene B through P.B' inclusive (Table 5).

The ability of $\lambda$ immune recipients to block transduction, together with the knowledge that the donor's $\lambda$ prophage is located near the galactose operon, has led to the hypothesis that enhanced transduction is mediated by T1 particles which carry a hybrid of bacterial and $\lambda$ DNA; the abbreviation for these particles is $(\lambda-g a l)$ T1. Furthermore, it is hypothesized that one or more $\lambda$ genes cause the enhancing effect through their expression in a $\lambda$-sensitive recipient.

The size of the hybrid DNA of $(\lambda-g a l) T 1$ must be approximately the same size of the T1 chromosome because the density of the transducing particles is not significantly different from the density of T1 plaque-forming ability (Drexler, unpublished observations). Since T1 and $\lambda$ contain almost identical amounts of DNA $(4,12)$, the hybrids likewise must contain about the same amount of DNA as a $\lambda$ chromosome. Because 
the galactose operon is near the attachment site of $\lambda$ (Fig. 1), the simplest model is one in which the DNA of the hybrid is a continuous piece of DNA beginning at the left of the $\mathrm{Gal}^{+}$marker and terminating within the prophage. Whether there is a family of transducing particles as opposed to particles which carry a specific piece of DNA cannot be determined from the data in this report. However, the dependence of enhanced transduction of a functional $\mathrm{N}^{+}$gene indicates that the particles responsible for the increase in transduction must terminate to the right of $\mathbf{N}$. The increase in transduction which occurs when donors contain a prophage with an $\mathbf{O}$ or $\mathbf{P}$ mutation shows that in some particles termination must be to the right of gene $P$.

The almost complete dependence of enhanced transduction on the function of the bacterium's $\mathrm{Rec}^{+}$system (Table 4), together with the absence of an effect of mutations in the red, int, and xis genes, suggests that transduction occurs by normal processes; that is to say, by means of homologies in the donor and recipient DNA and crossovers mediated by the recipient cell. No evidence has been obtained which would indicate that donor prophage DNA is incorporated into the transductants. On the contrary, the transductants are stable and nonimmune and therefore must arise by a completely different mechanism than the most common type of transduction mediated by the hybrid $\lambda \mathrm{dg}$, namely, by means of lysogenization.

The precise mechanism by which $\lambda$ genes can, as part of a $\lambda$-gal hybrid, cause enhanced transduction of a marker on the bacterial part of the hybrid cannot be determined from the data presented here. The dependence of transduction on the cell's $\operatorname{Rec}^{+}$system seems to eliminate a role for a $\lambda$-determined nuclease which mediates general recombination; DNA replication initiated by $\lambda$ and the action of a late function have also been eliminated. The effect of a mutation in gene $\mathbf{N}$ is so pleiotropic as to give no clue as to the specific function which is effected (22). Likewise, the sensitivity to immunity repression is no help in determining the specificity of the phenomenon. In the accompanying paper, experiments are presented which indicate that enhanced transduction is under the same control as transcription of the $\lambda$ chromosome and that transcription per se may be responsible for enhancedtransduction of $\mathrm{Gal}^{+}$by $(\lambda-g a l) \mathrm{T} 1$

\section{ACKNO WLEDGMENTS}

I am grateful to all those colleagues who supplied me with strains of bacteria and phages as well as antiserum. I give special thanks to Allan Campbell who extended many courtesies to me during the course of this work.

Conversations with $\mathrm{L}$. Kucera as well as a reading of these manuscripts by L. Kucera and S. H. Richardson were of great value to me.

The competent technical assistance of Mrs. Lindsay R. Lambe and Laura Winstead is greatly appreciated.

This work was supported by Public Health Service grant number AI 07107 from the Institute of Allergy and Infectious Diseases and by a grant from the United Medical Research Fund of North Carolina.

\section{LITERATURE CITED}

1. Arber, W., G. Kellenberger, and J. Weigle. 1957. La defectuosite du phage lambda transducteur. Schweiz. Z. Allge. Pathol. Bakteriol. 20:659-665.

2. Campbell, A. 1957. Transduction and segregation in Escherichia coli $\mathrm{K} 12$. Virology 4:366-384.

3. Campbell, A. 1961. Sensitive mutants of bacteriophage $\lambda$. Virology 14:22-32.

4. Caro, L. G. 1965. The molecular weight of lambda DNA. Virology 25:226-236.

5. Clark, A. J., and A. D. Margulies. 1965. Isolation and characterization of recombination-deficient mutants of Escherichia coli K12. Proc. Nat. Acad. Sci. U.S.A. 53:451-459.

6. Dove, W. F. 1966. Action of the lambda chromosome. I. Control of functions late in bacteriophage development. J. Mol. Biol. 19:187-201.

7. Drexler, H. 1970. Transduction by bacteriophage T1. Proc. Nat. Acad. Sci. U.S.A. 66:1083-1088.

8. Echols, H., and R. Gingery. 1968. Mutants of bacteriophage $\lambda$ defective in vegetative genetic recombination. J. Mol. Biol. 34:239-249.

9. Guarneros, G., and H. Echols. 1970. New mutants of bacteriophage $\lambda$ with a specific defect in excision from the host chromosome. J. Mol. Biol. 47:565-574.

10. Howard-Flanders, P., and L. Theriot. 1966. Mutants of Escherichia coli $\mathrm{K} 12$ defective in DNA repair and in genetic recombination. Genetics 53:1137-1150.

11. Joyner, A., L. N. Isaacs, and H. Echols. 1966. DNA replication and messenger RNA production after induction of wild-type $\lambda$ bacteriophage and $\lambda$ mutants. J. Mol. Biol. 19: 174-186.

12. Lang, D., H. Bujard, B. Wolff, and D. Russell. 1967. Electron microscopy of size and shape of viral DNA in solutions of different ionic strength. J. Mol. Biol. 23:163-181.

13. Lederberg, E. M. 1951. Lysogenicity in E. coli K12. Genetics 36:560.

14. Lederberg, J. 1950. Isolation and characterization of biochemical mutants of bacteria, p. 5. In J. H. Comrie, Jr. (ed.), Methods in medical research, vol. 3. Yearbook Publishers, Chicago, Ill.

15. Michalke, W. 1967. Erhöte Rekombinationshäufigeit an den Enden des T1-Chromosoms. Mol. Gen. Genet. 99:12-33.

16. Morse, M. L., E. M. Lederberg, and J. Lederberg. 1956a. Transduction in Escherichia coli K-12. Genetics 41:142-156.

17. Morse, M. L., E. M. Lederberg, and J. Lederberg. 1956b. Transductional heterogenotes in Escherichia coli. Genetics 41:758-779.

18. Signer, E. R. 1964. Recombination between coliphages $\lambda$ and 180. Virology 22:650-651.

19. Signer, E. R. 1969. Plasmid formation: a new mode of lysogeny by phage $\lambda$. Nature (London) 223:158-160.

20. Signer, E. R., and J. Weil. 1968. Recombination in bacteriophage $\lambda$. I. Mutants deficient in general recombination. J. Mol. Biol. 34:261-271.

21. Signer, E. R., J. Weil, and P. C. Kimball. 1969. Recombination in bacteriophage $\lambda$ III. Studies on the nature of the prophage attachment region. J. Mol. Biol. 46:543-563. 
22. Skalka, A., B. Butler, and H. Echols. 1967. Genetic control of transcription during development of phage $\lambda$. Proc. Nat. Acad. Sci. U.S.A. 58:576-583.

23. Stahl, M. M., and F. W. Stahl. 1971. DNA synthesis associated with recombination p. 431-442. I. Recombination in a DNA-negative host. In A. D. Hershey (ed.), The bacteriophage lambda. Cold Spring Harbor Laboratory, Cold Spring Harbor, N.Y.

24. Stahl, F. W., and M. M. Stahl. 1971. DNA synthesis associated with recombination. II. Recombination between repressed chromosomes, p. 443-453. In A. D. Hershey (ed.), The bacteriophage lambda. Cold Spring Harbor Laboratory, Cold Spring Harbor, N.Y.

25. Taylor, A. L. 1970. Current linkage map of Escherichia coli. Bacteriol. Rev. 34:155-175.

26. Wood, W. B. 1966. Host specificity of DNA produced by Escherichia coli: bacterial mutants affecting the restriction and modification of DNA. J. Mol. Biol. 16:118-133.

27. Zissler, J. 1967. Integration-negative (int) mutants of phage $\lambda$. Virology 31:189. 